\title{
Dnmt3a in the Medial Prefrontal Cortex Regulates Anxiety- Like Behavior in Adult Mice
}

\author{
Evan Elliott, ${ }^{1,2 \star}$ Sharon Manashirov, ${ }^{1,3 \star}$ Raaya Zwang, ${ }^{1}$ Shosh Gil, ${ }^{1}{ }^{\circledR}$ Michael Tsoory, ${ }^{4}$ Yair Shemesh, ${ }^{1,3}$ and Alon Chen ${ }^{1,3}$ \\ ${ }^{1}$ Department of Neurobiology, Weizmann Institute of Science, Rehovot, 76100, Israel, ${ }^{2}$ Faculty of Medicine, Bar Ilan University, Safed, 13215, Israel, \\ ${ }^{3}$ Department of Stress Neurobiology and Behavioral Neurogenetics, Max Planck Institute of Psychiatry, Munich, 80804, Germany, and ${ }^{4}$ Department of \\ Veterinary Resources, Weizmann Institute of Science, Rehovot, 76100, Israel
}

Recently, it has been suggested that alterations in DNA methylation mediate the molecular changes and psychopathologies that can occur following trauma. Despite the abundance of DNA methyltransferases (Dnmts) in the brain, which are responsible for catalyzing DNA methylation, their roles in behavioral regulation and in response to stressful challenges remain poorly understood. Here, we demonstrate that adult mice which underwent chronic social defeat stress (CSDS) displayed elevated anxiety-like behavior that was accompanied by a reduction in medial prefrontal cortex (mPFC)-DNA methyltransferase 3a (Dnmt3a) mRNA levels and a subsequent decrease in mPFCglobal DNA methylation. To explore the role of mPFC-Dnmt3a in mediating the behavioral responses to stressful challenges we established lentiviral-based mouse models that express lower (knockdown) or higher (overexpression) levels of Dnmt3a specifically within the mPFC. Nonstressed mice injected with knockdown Dnmt3a lentiviruses specifically into the mPFC displayed the same anxiogenic phenotype as the CSDS mice, whereas overexpression of Dnmt3a induced an opposite, anxiolytic, effect in wild-type mice. In addition, overexpression of Dnmt3a in the mPFC of CSDS mice attenuated stress-induced anxiety. Our results indicate a central role for mPFCDnmt3a as a mediator of stress-induced anxiety.

Key words: anxiety; DNA methyltransferases; stress

\section{Significance Statement}

DNA methylation is suggested to mediate the molecular mechanisms linking environmental challenges, such as chronic stress or trauma, to increased susceptibility to psychopathologies. Here, we show that chronic stress-induced increase in anxiety-like behavior is accompanied by a reduction in DNA methyltransferase 3a (Dnmt3a) mRNA levels and global DNA methylation in the medial prefrontal cortex (mPFC). Overexpression or knockdown of mPFC-Dnmt3a levels induces decrease or increase in anxietylike behavior, respectively. In addition, overexpression of Dnmt3a in the mPFC of chronic stressed mice attenuated stress-induced anxiety. We suggest that mPFC-Dnmt3a levels mediates anxiety-like behavior, which may be a primary molecular link between chronic stress and the development of anxiety disorders, including post-traumatic stress disorder.

\section{Introduction}

Epigenetic modifications, particularly DNA methylation, have been implicated as key molecular drivers of stress-induced psy-

\footnotetext{
Received March 12, 2015; revised Nov. 17, 2015; accepted Nov. 25, 2015

Author contributions: E.E., S.M., and A.C. designed research; E.E., S.M., R.Z., S.G., Y.S., and A.C. performed research; Y.S. contributed unpublished reagents/analytic tools; E.E., S.M., M.T., and A.C. analyzed data; E.E., S.M., and A.C. wrote the paper.

This work was supported by European Research Council FP7 Grant 260463, Israel Science Foundation Research Grants 803/11 and 1565/15, Roberto and Renata Ruhman, Nella and Leon Benoziyo Center for Neurological Diseases, the Henry Chanoch Krenter Institute for Biomedical Imaging and Genomics, the Perlman Family Foundation (founded by Louis L. and Anita M. PerIman), the Adelis Foundation, the Irving I. Moskowitz Foundation, I-CORE Program of the Planning and Budgeting Committee, and Israel Science Foundation Grant 1916/12. We thank Dr. Jessica Keverne for professional English editing, formatting, and scientific input; and Sharon Ovadia for devoted assistance with animal care.

The authors declare no competing financial interests.

*E.E. and S.M. contributed equally to this study.

Correspondence should be addressed to Prof. Alon Chen, Department of Neurobiology, Weizmann Institute of Science, Rehovot, 76100, Israel, E-mail: alon.chen@weizmann.ac.il; or Department of Stress Neurobiology and
}

chopathological behavior. Accumulating evidence in murine studies suggests that psychological stress can dysregulate the DNA methylation pattern of multiple stress-related genes in the brain (Murgatroyd et al., 2009; Roth et al., 2009; Uchida et al., 2011; Roth, 2013). There is also evidence of DNA methylation dysregulation in humans with psychopathological conditions, including depression and suicide (Poulter et al., 2008; Keller et al., 2010).

Despite the mounting evidence of stress-induced changes in DNA methylation in the brain, we are only beginning to gain knowledge of the functional roles of the DNA methyltransferases (Dnmts) in stress-induced behaviors. This could prove beneficial

Neurogenetics, Max-Planck Institute of Psychiatry, Munich, 80804, Germany, E-mail: alon_chen@psych.mpg.de. DOI:10.1523/JNEUROSCI.0971-15.2016

Copyright $\odot 2016$ the authors $\quad 0270-6474 / 16 / 360730-11 \$ 15.00 / 0$ 
considering that there are already pharmacological tools available that inhibit Dnmt activity. Initial studies have found that fear conditioning induces an increase in the expression of Dnmt3a in the hippocampus and that pharmacological inhibition of Dnmts in that same brain area can impair short-term learning (Miller and Sweatt, 2007), whereas inhibition of Dnmts in the frontal cortex can erase remote memories of fear (Miller et al., 2010). Transgenic studies of mice lacking both Dnmt1 and Dnmt3a in forebrain excitatory neurons exhibit an attenuated hippocampaldependent learning (Feng et al., 2010), and Dnmt3a expression in the nucleus accumbens (NAc) promotes depression-like behavior in the social defeat procedure (LaPlant et al., 2010). Therefore, the endogenous role of Dnmts in psychological behavior is both brain region specific and variable among the different Dnmts.

The brains' limbic system is central in orchestrating the systemic and behavioral response to stress. While activation of the amygdala can promote an enhanced stress response, prefrontal cortex (PFC) innervations of the amygdala can attenuate this response (Herman et al., 2005). Multiple lines of evidence have shown that the PFC is highly susceptible to stressful challenges and can undergo morphological changes following chronic stress (Arnsten, 2009). Both murine and human imaging studies have shown that dysregulation of the amygdala and PFC (decreased activity) are present in individuals with anxiety disorders and post-traumatic stress disorder (PTSD) (for review, see Yehuda and LeDoux, 2007). Therefore, molecular mechanisms that are dysregulated in the PFC are likely to be involved in stress-induced anxiety and PTSD.

In this study, using the chronic social defeat stress (CSDS) procedure, well established for the induction of prolonged anxiety-like behavior in rodents (Krishnan et al., 2007), we sought to examine the role of limbic Dnmts in anxiety-like behavior. Toward this end, we identified which specific Dnmts were dysregulated in various brain regions following CSDS. Here, we show that the elevation in anxious behavior following CSDS accompanies a robust reduction in Dnmt3a mRNA levels and global DNA methylation in the medial PFC (mPFC). Next, we genetically manipulated the Dnmt3a expression levels in naive mice and tested the behavioral phenotype. We also examined the potential of Dnmt3a as an anxiolytic agent by overexpressing Dnmt3a in the mPFC of chronic-stressed mice. Our data suggest that expression of Dnmt3a in the mPFC mediates anxiety-like behavior, which may be a primary molecular link between chronic stress and the development of anxiety behaviors and disorders, including PTSD.

\section{Materials and Methods}

\section{Animals}

Adult (9-week old) C57BL/6J mice (Harlan) were maintained in a pathogen-free temperature-controlled $\left(22 \pm 1^{\circ} \mathrm{C}\right)$ mouse facility on a reverse $12 \mathrm{~h}$ light-dark cycle at the Weizmann Institute of Science, according to institutional guidelines. Food (Harlan) and water were given ad libitum. All experimental protocols were approved by the Institutional Animal Care and Use Committee of the Weizmann Institute of Science.

\section{Chronic social defeat stress}

Nine-week-old C57BL/6J mice were subjected to a CSDS protocol as previously described (Krishnan et al., 2007). Briefly, the mice were placed in the home cage of an aggressive ICR (CD1) outbred mouse (Harlan) and allowed to physically interact for $5 \mathrm{~min}$. During this time, the ICR mouse attacked the intruder mouse and the intruder displayed subordinate posturing. A perforated clear Plexiglas divider was then placed between the animals, and the mice remained in the same cage for $24 \mathrm{~h}$ allowing sensory contact. The procedure was then repeated with an unfamiliar ICR mouse for each of the 10 consecutive days. Control mice were housed in the same room as the social defeat mice but were taken out of the room during the $5 \mathrm{~min}$ interaction with the ICR. Control mice were handled daily and housed two per cage separated by a perforated clear Plexiglas divider.

\section{Behavioral assessments}

All behavioral assessments were performed during the dark phase following a $2 \mathrm{~h}$ habituation to the test room before each test. Behavioral tests were conducted in the following order, from the least stressful procedure to the most stressful, ending with locomotor testing: open field, dark-light transfer (DLT), elevated plus maze (EPM), and home cage locomotion.

Open-field test. The open-field test was performed in a $50 \times 50 \times 22$ $\mathrm{cm}$ white box, lit to 120 lux. The mice were placed in the box for $10 \mathrm{~min}$. Locomotion in the box was quantified using a video tracking system (VideoMot2; TSE Systems).

DLT test. The DLT test apparatus consists of a polyvinyl chloride box divided into a black dark compartment $(14 \times 27 \times 26 \mathrm{~cm})$ and a connected white 1200 lux illuminated light compartment $(30 \times 27 \times 26 \mathrm{~cm})$. During the 5 min test, the time spent in the light compartment, the distance traveled in light area, and the number of light-dark transitions were quantified with a video tracking system (VideoMot2; TSE Systems).

EPM. The apparatus in the EPM test is a plus sign shape containing 2 barrier walls and 2 open arms. During the 5 min test, which is performed in relative darkness (6 lux), the number of entries, the distance traveled, and the time spent in the open arms are automatically scored using a video tracking system (VideoMot2, TSE Systems).

Home cage locomotion. Home cage locomotion was assessed using the InfraMot system (TSE Systems). Mice were housed individually for $72 \mathrm{~h}$, of which the first $24 \mathrm{~h}$ were considered habituation to the individual housing conditions. Measurements of general locomotion consisted of two light and two dark cycles in the last $48 \mathrm{~h}$, collected at $10 \mathrm{~min}$ intervals.

\section{Microdissection and preparation of RNA}

Immediately after decapitation, the brain was removed and placed into a $1 \mathrm{~mm}$ metal matrix (catalog \#51380; Stoelting). The brain was sliced using standard razor blades (GEM, 62-0165) into 1 or $2 \mathrm{~mm}$ slices that were quickly frozen on dry ice. Blunted syringes of different diameters were used to extract the brain regions from slices removed from the matrix, which were then stored at $-80^{\circ} \mathrm{C}$. RNA extraction was performed using NucleoSpin RNA XS kit (Macherey-Nagel). RNA was reverse transcribed to cDNA using the High Capacity RNA to cDNA kit (Applied Biosystems). The cDNA was then analyzed by qRT-PCR.

Genomic DNA purification and global DNA methylation analysis The 14-gauge punches from mouse mPFC were incubated overnight at $50^{\circ} \mathrm{C}$ in $400 \mu$ l lysis buffer containing Proteinase K. Tissue was then fully suspended in solution by vigorous pipetting. Solution was cleared of debris by a 5 min centrifugation at $16,000 \times g$, followed by DNA precipitation with $500 \mu \mathrm{l}$ isopropanol and $15 \mathrm{~min}$ centrifugation at $4^{\circ} \mathrm{C}$. DNA was washed with $70 \%$ ethanol, centrifuged at $16,000 \times g$ for an additional $5 \mathrm{~min}$, and then resuspended in $30 \mu \mathrm{l}$ double deionized water; $100 \mathrm{ng}$ of genomic DNA was used for DNA global methylation analysis performed with the MethylFlash Methylated DNA Quantification Kit (Colorimetric; Epigentek Group) according to the manufacturer's instructions. Raw values were quantified, and methylation levels were estimated using a standard curve of methylated DNA standard provided by the manufacturer. Values are presented as methylation percent relative.

\section{$q R T-P C R$}

We used qRT-PCR to detect the levels of mRNA both in the in vitro and in vivo experiments. The expression of HPRT mRNA served as the internal control. The RT-PCR was performed using a 7500 RT-PCR system (Applied Biosystems) using fluorescent SYBR Green technology (ABgene). The PCR conditions were as follows: cDNA equivalent to 10 ng of total RNA was amplified by PCR for 45 cycles at an annealing temperature of $60^{\circ} \mathrm{C}$. Each qPCR contained $10 \mu \mathrm{l} 2 \times$ SYBR Green Mastermix, and a final primer concentration of $250 \mathrm{~nm}$. The specificity of the amplification products was verified by melting curve analysis. Primer sequences used were as follows: Dnmtl sense, 5'CCTAGTTCCGTGGC 
TACGAGGAGAA3'; Dnmt1 antisense, 5'TCTCTCTCCTCTGCAGC CGACTCA3'; Dnmt3a1 sense, 5'CCTAGTTCCGTGGCTACGAGG AGAA3'; Dnmt3al antisense, 5'TCTCTCTCCTCTGCAGCCGACTCA3'; Dnmt3a2 sense, 5'GCAGCTATTTACAGAGCTTC3'; Dnmt3a2 antisense, 5'TCCTCCACCTTCTGAGACT3'; Dnmt3b sense, 5'TTCAGTGACC AGTCCTCAGACACGAA3'; Dnmt3b antisense, 5'TCAGAAGGCTGG AGACCTCCCTCTT3'; and HPRT sense, 5'GCAGTACAGCCCCAA AATGG3'; HPRT antisense, 5'GGTCCTTTTCACCAGCAAGCT3'.

Lentiviral vectors, infection, and expression

DNMT3a knockdown. Lentiviral vectors were constructed to produce lentiviruses expressing short hairpin RNA (shRNA) against Dnmt3a transcripts or scrambled control. Five different target sequences (see Fig. $2 A$ ) from the open reading frame of a Dnmt3a mouse cloned to the pLKO.1 plasmid following a U6 promoter were obtained (SigmaAldrich), and high titer lentiviruses were produced (see Fig. 2C) as described previously (Tiscornia et al., 2006). Briefly, recombinant lentiviruses were produced by transient transfection in HEK293T cells. Infectious particles were harvested at 48 and $72 \mathrm{~h}$ after transfection, filtered through $0.45-\mu \mathrm{m}$-pore cellulose acetate filters, concentrated by ultracentrifugation, redissolved in sterile HBSS, aliquoted, and stored at $-80^{\circ} \mathrm{C}$. The most efficient shRNA-shDnmt3a\#1 (CCGGCCAGATGT TCTTTGCCAATAACTCGAGTTATTGGCAAAGAACATCTGGTTTT TG) that targets both Dnmt3a isoforms-1 and -2, was selected for the in vivo experiments (see Fig. 2C).

Dnmt3a1 overexpression. Lentiviral vectors were designed and constructed to produce lentiviruses expressing mouse DNMT3a1. DNMT3a1, isolated from mouse brain cDNA using RT-PCR, was subcloned into BamH1 restriction enzyme site between the CMV promoter and the IRES-GFP sequence of the lentiviral expression vector, pCSC-SP-PW-CMV-IRES/GFP (kindly provided by Dr Inder Verma, Salk Institute for Biological Studies, La Jolla, CA). Lentiviruses were produced as described above.

\section{In vitro validation of Dnmt3aKD lentiviral vectors}

The ability of the shDnmt3a vectors to knock down Dnmt3a mRNA and protein expressions was assessed using RT-PCR and Western blot analysis, respectively.

$R T-P C R$. N2a cells were infected with the five different shDnmt3a lentiviruses. At $72 \mathrm{~h}$ after infection, cells were lysed and the RNA extracted using Tri reagent (Beit Haemek Biological Industries) according to the manufacturer's protocol. RNA was reverse transcribed to cDNA using the High Capacity RNA to cDNA kit (Applied Biosystems). The cDNA was then analyzed using qRT-PCR.

Western blot. N2a cells were infected with the shDnmt3a\#1 lentiviruses. At $72 \mathrm{~h}$ after infection, cells were harvested in lysis buffer $[25 \mathrm{~mm}$ Tris- $\mathrm{HCl}, \mathrm{pH}$ 7.4, $150 \mathrm{~mm} \mathrm{KCl}, 1.5 \mathrm{~mm} \mathrm{MgCl}_{2}, 1 \%$ (w/v) glycerol, $1 \%$ $(\mathrm{w} / \mathrm{v})$ NP40] containing protease inhibitors. Cell lysates were subjected to gel electrophoresis on $10 \%$ SDS-polyacrylamide gel, and separated proteins were transferred onto nitrocellulose membranes and probed with rabbit antiserum against Dnmt3a at a final dilution of 1:2000 (Santa Cruz Biotechnology). Subsequently, membranes were incubated with HRP-conjugated anti-rabbit secondary antibody.

\section{In vivo validation of lentiviral vectors}

Brain samples were taken from Dnmt3aKD or Dnmt3aloverexpressing $(\mathrm{OE})$ and control injected mice $14 \mathrm{~d}$ after the injection from the mPFC. After removing the brain and placing it on an acryl $1 \mathrm{~mm}$ brain matrix (catalog \#51380; Stoelting), $2 \mathrm{~mm}$ slices were taken based on designated anatomical markers using standard razor blades (GEM, 62-0165). Blunted syringes of different diameters were used to extract the brain regions from slices removed from the matrix. RNA extraction and RNA reverse transcription were performed, and the relative quantities were assessed using RT-PCR.

\section{Stereotactic intracranial injections}

Injections were performed as previously described (Sztainberg et al., 2010). Briefly, adult (9-week-old) C57BL/6 male mice (Harlan) received bilateral stereotaxic injections of lentivirus into the mPFC ( $1 \mu \mathrm{l}$ of lentivirus per hemisphere, $0.1 \mu \mathrm{l} / \mathrm{min}$ ). Mice were anesthetized with isoflu- rane and placed on a computer-guided sterotaxic instrument (Angle Two Stereotaxic Instrument, Neurolab, Leica Microsystems). The lentiviral vectors were delivered using a Hamilton syringe connected to a motorized nanoinjector. Vectors were injected into coordinates, relative to bregma: anteroposterior $2.0 \mathrm{~mm}$, lateral-medial $\pm 0.3 \mathrm{~mm}$, dorsalventral $-2.8 \mathrm{~mm}$, based on a calibration study that indicated that these coordinates led to the $\mathrm{mPFC}$ in C57BL/6 strain on our system. Mice were subjected to behavioral studies following a 2 week recovery period.

\section{Immunohistochemistry}

Mice were anesthetized with chloral hydrate ( $1.4 \mathrm{~g} / \mathrm{kg}$ body weight, i.p.) and transcardially perfused with $10 \mathrm{ml}$ PBS followed by $100 \mathrm{ml} \%$ PFA in borate buffer, $\mathrm{pH} 9.5$. The brains were removed and postfixed overnight in $4 \%$ PFA $+30 \%$ sucrose at $4^{\circ} \mathrm{C}$. Free-floating $30 \mu \mathrm{m}$ coronal mPFC sections were collected using a microtome (Leica Microsystems) and stored in PBS at $4^{\circ} \mathrm{C}$ until use. For GFP immunostaining, we used a biotinylated anti-GFP antibody raised in rabbit as the primary antibody (Abcam) and streptavidin Cy2 conjugated as the secondary antibody (Jackson ImmunoResearch Laboratories).

\section{Bioinformatics}

Prediction of putative glucocorticoid response element sequences in the promoter region of DNMT3a gene was done using the UCSC genome browser (to define the genomic region). The MatInspector program from the Genomatix Genome Analyzer package (Genomatix Software) was used for the prediction of potential transcription factor binding sites.

\section{Statistical analysis}

Data are expressed as mean \pm SEM. Statistical analyses were performed using Statistical Package for the Social Sciences software, version 16 (SPSS). All datasets' distributions were tested for normality using Shapiro-Wilks test to determine which tests should be applied. In cases where indices of two groups were compared and the data's distribution was normal, the independent Student's $t$ test was used. When the data departed from normality, the Mann-Whitney $U$ test was applied. Where indices from more than two groups were compared, and the data's distribution was normal, one-way ANOVA followed by post hoc planned contrasts comparisons (independent Student's $t$ test, Bonferroni corrected for multiple comparisons) was applied. For analysis of locomotor activity, the one-way ANOVA with repeated measures was used to compare the different time points between the groups.

\section{Results}

Chronic social defeat stress regulates anxiety-like behavior and transcriptional regulation of Dnmt3a1 in the mPFC

The CSDS procedure has been shown to cause a long-lasting increase in anxiety-like behavior in mice (Krishnan et al., 2007). To ensure replication of these behavioral phenotypes, mice were tested for anxiety-like behavior using the EPM and DLT tests 2 weeks after the last day of CSDS. As expected, CSDS mice displayed increased anxiety-like behavior. Shapiro-Wilks test indicated that the data departed from normality; therefore, a nonparametric analysis was performed. There was a statistically significant reduction in the time spent in the open arms $(n=5$, $U=3.0, p=0.022$; Fig. $1 A)$, distance traveled in the open arms $(n=5, \mathrm{U}=3.0, p=0.022$; Fig. $1 B)$, and number of visits to the open arms $(n=5, U=0.50, p=0.005$; Fig. $1 C)$. The CSDS mice also displayed an anxious phenotype in the DLT test whereby they spent less time in $\left(n=13\right.$ or $14, T_{(25)}=3.805, p=0.001$; Fig. $1 D)$, walked less distance in $\left(n=13\right.$ or $14, T_{(25)}=5.185, p=$ 0.000 ; Fig. $1 E)$, and made less visits to $\left(n=13\right.$ or $14, T_{(25)}=4.014$, $p=0.000$; Fig. $1 F$ ) the light chamber than controls. Assessment of locomotor activity in the home cage across the circadian cycle revealed no differences between the control and CSDS groups (data not shown).

As a first step to determine whether Dnmts play a role in the long-lasting anxiogenic effects observed following CSDS, we 
A

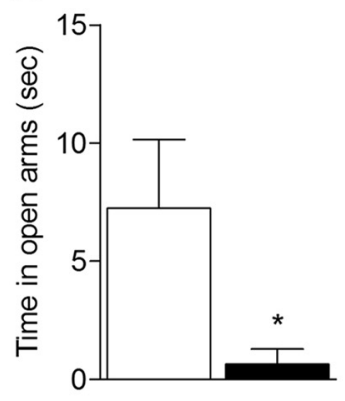

D

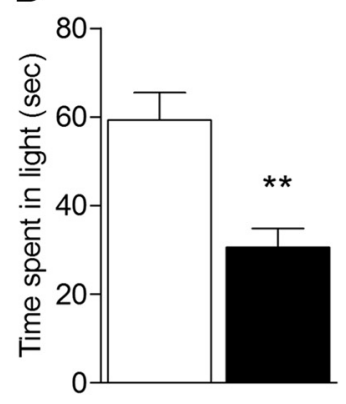

G

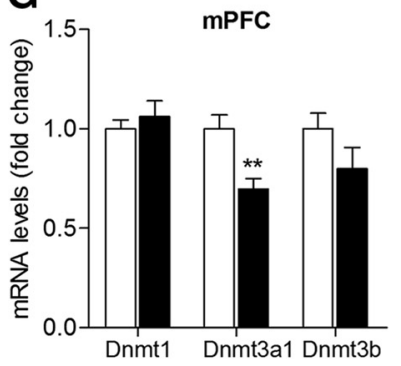

B

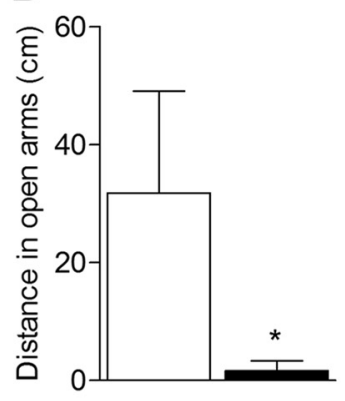

E

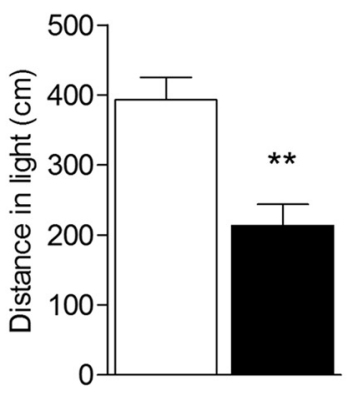

H

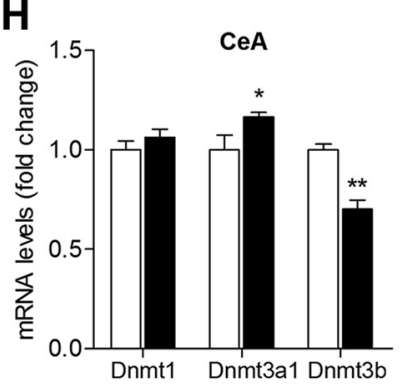

C

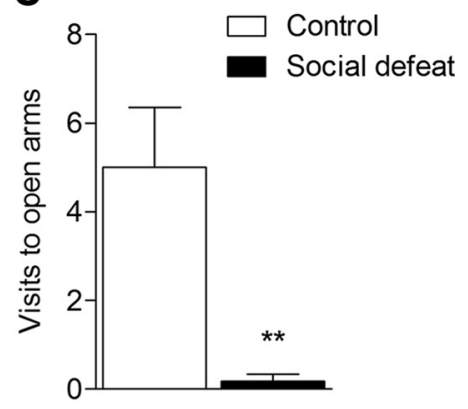

F

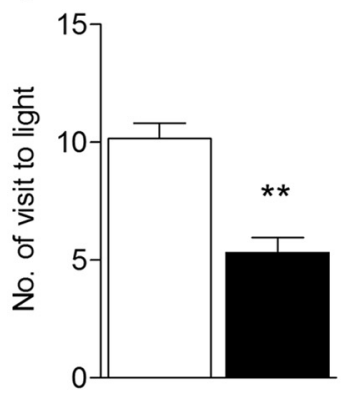

I

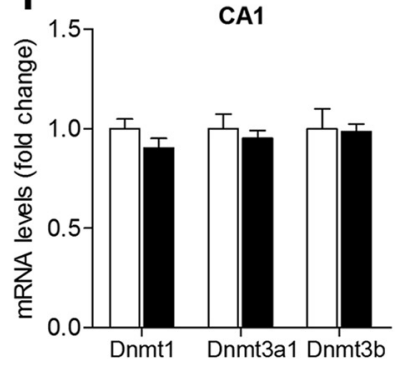

J mPFC-baseline $\mathbf{K}$

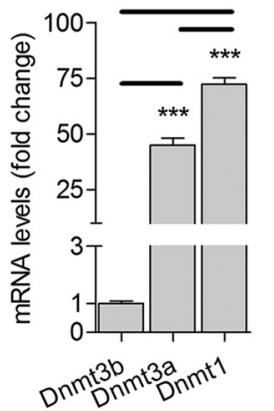

K L

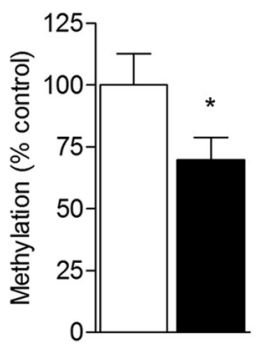

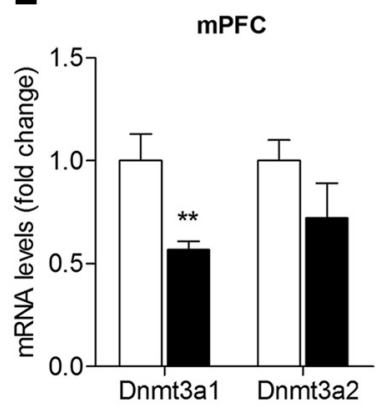

M

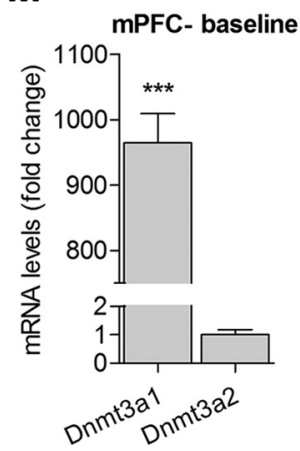

Figure 1. $\quad \boldsymbol{A}-\boldsymbol{F}$, Increase in anxiety-like behavior in mice subjected to CSDS as measured by the EPM and DLT tests. In the EPM test, CSDS mice showed ( $\boldsymbol{A})$ a significant reduction in the time spent in, (B) distance traveled, and $(\boldsymbol{C})$ made significantly fewer visits to the open arms compared with control mice. $n=5$ (Mann-Whitney $U$ test). In the DLT test, CSDS mice showed a significant reduction in (D) time spent in, $(\boldsymbol{E})$ distance traveled in, and $(\boldsymbol{F})$ made fewer entries into the light compartment compared with controls. $n=13$ or 14 (Students' $t$ test). $\mathbf{G}-\mathbf{I}$, Transcriptional regulation of mPFC-Dnmt3a by CSDS. mRNA levels of Dnmt1, Dnmt3a, and Dnmt3b were determined in stress-related brain areas following the CSDS protocol, using qRT-PCR analysis. G, Dnmt3a mRNA levels were found to be significantly downregulated in the mPFC of CSDS mice compared with controls. $\boldsymbol{H}$, Dnmt3a mRNA levels were significantly upregulated, whereas Dnmt3b mRNA levels were significantly downregulated in the central amygdala (CeA) of CSDS mice. I, No significant differences were found in Dnmts' transcripts in the CA1. $n=4-7$ (Student's $t$ test). J, Dnmt 1 basal mRNA expression in the mPFC is significantly higher in comparison to Dnmt3a, which in turn is significantly higher in comparison to Dnmt3b. $n=13$ (one-way ANOVA followed by Student's t test). $\boldsymbol{K}$, Global DNA methylation was significantly decreased in the mPFC 4 weeks following CSDS. $L, M$, Expression of Dnmt3a splice variants in the mPFC. $L$, mPFC-Dnmt3a1 mRNA levels are downregulated following CSDS, whereas Dnmt3a2 has no significant change. $M$, Dnmt3a1 basal mRNA levels in the mPFC are significantly higher compared with Dnmt3a2levels. $n=5-8$ (Student's t test). ${ }^{*} p<0.05 .{ }^{* *} p<0.01$. ${ }_{* * *} p<0.001$. Data are mean \pm SEM.

quantified the mRNA levels of all known Dnmts using RT-PCR in the forebrain centers known to be related to anxiety at week 3 (i.e., after the last day of CSDS) (Fig. $1 G-I$ ). We found that Dnmt3a was selectively downregulated in the $\operatorname{mPFC}(n=6$ or 7 ,
$T_{(11)}=-3.485, p=0.005$; Fig. $\left.1 G\right)$ and upregulated in the central amygdala $(\mathrm{CeA})\left(n=5\right.$ or $6, T_{(9)}=2.339, p=0.044$; Fig. $1 H)$. In contrast, CeA-Dnmt3b was significantly downregulated $\left(n=4-7, T_{(9)}=-3.970, p=0.003\right.$; Fig. $\left.1 H\right)$. Interestingly, no 
significant differences in any of the Dnmts' mRNA levels were observed in the CA1 region of the hippocampus (Fig. 1I) or in the bed nucleus of the stria terminalis (data not shown). We further examined the relative mRNA expression of the different Dnmts in the mPFC. Our results are in line with the literature and indicate significant differences between the groups, where Dnmt1 is the most abundant in this area with 1.6-fold change relative to Dnmt3a $\left(n=13, T_{(24)}=-5.830, p=0.000\right.$, one-way ANOVA followed by Student's $t$ test; Fig. $1 \mathrm{~J}$ ) and 72 -fold change relative to Dnmt3b $\left(n=13, T_{(24)}=-44.724, p=0.000\right.$, one-way ANOVA followed by Student's $t$ test; Fig. $1 J$ ). Dnmt3a is the second most abundant with mRNA expression levels that are 45-fold higher relative to Dnmt3b $\left(n=13, T_{(24)}=-33.759, p=0.000\right.$, one-way ANOVA followed by Student's $t$ test; Fig. $1 J$ ).

Given the fact that we observed a robust reduction of Dnmt3a within the mPFC of stressed mice, we focused our following experiments on this brain region. We first examined whether the downregulation of mPFC-Dnmt3a observed after CSDS had an effect on the global methylation levels in this area. To that end, we checked global DNA methylation levels in the mPFC of mice, 4 weeks after CSDS. There was a significant reduction in the methylation levels in the MPFC of the CSDS mice $\left(n=8, T_{(14)}=\right.$ $-2.140, p=0.05$; Fig. $1 K$ ). Dnmt3a has two different splice variants, Dnmt3a1 and Dnmt3a2; we designed primers to distinguish them and checked their baseline relative mRNA expression levels in the mPFC. The results indicated $\sim 1000$-fold difference in their expression levels, with Dnmt3a1 being much more abundant in this area $\left(n=7, T_{(12)}=-42.011, p=0.000\right.$; Fig. $\left.1 M\right)$. Next, we checked their mRNA levels in the mPFC following CSDS compared with the unstressed control group. The mPFCDnmt3a1 mRNA levels were significantly reduced following $\operatorname{CSDS}\left(n=5\right.$ or $6, T_{(9)}=-3.732, p=0.005$; Fig. $\left.1 L\right)$, whereas no significant change was detected in the levels of Dnmt3a2.

To explore possible mechanisms by which CSDS regulates Dnmt3a expression, we checked for putative glucocorticoid binding sites in the promoter region of Dnmt3al. We found a negative glucocorticoid response element sequence $150 \mathrm{bp}$ upstream of the DNMT3al transcription start site, in the nucleotide sequence TGCCTCCCGGGCGGCT. This negative regulatory site has a very specific matrix, therefore decreasing the possibility of nonspecific binding, and specifically binds NR3C1.

\section{Establishment and validation of shRNA viral constructs for Dnmt3a knockdown}

Because we observed robust changes in mPFC-Dnmt3a levels following CSDS, we sought to manipulate the endogenous levels of Dnmt3a specifically in the mPFC of adult mice and check its effects on anxiety-like behavior. To this end, we established lentiviruses that overexpress different shRNA sequences designed to target the Dnmt3a transcript (Fig. 2A,B). To evaluate the efficiency of 5 different shDnmt3a constructs in reducing Dnmt3a mRNA expression, the mouse neuroblastoma cell line N2a was infected with the different shDnmt3a viral constructs or scrambled control. We compared the Dnmt3a mRNA expression level of each shDnmt3a-infected N2a cell to control infected cells. Four constructs significantly decreased the mRNA expression levels of Dnmt3a (Fig. $2 C)$, whereas shRNA\#1 $\left(n=4, T_{(3)}=5.962, p=\right.$ 0.009 , one-way ANOVA followed by Student's $t$ test) induced a $45 \%$ reduction in Dnmt3a mRNA expression levels. We further analyzed the efficiency of shDnmt3a\#1 to knock down the levels of Dnmt3a by comparing Dnmt3a protein levels in N2a cells infected with shDnmt3a\#1 to cells infected with scrambled con- trol viruses (Fig. 2D). Western blot analysis revealed a significant reduction in Dnmt3a protein levels in the shDnmt3a\#1-infected cells by $\sim 50 \%\left(n=4, T_{(6)}=3.496, p=0.013\right.$; Fig. $\left.2 E\right)$. To determine the efficiency of these viruses to knock down Dnmt3a in vivo, we compared the relative mRNA expression of Dnmt3a in the mPFC of mice injected with shDnmt3a to mice injected with the control virus. Micro-punching of mPFC was performed 3 weeks after injection, and mRNA levels were determined using qRT-PCR, which revealed a significant decrease in mPFCDnmt3a mRNA expression in mice injected with shDnmt3a $(n=$ $8, T_{(14)}=2.267, p=0.04$; Fig. $\left.2 F\right)$. We further performed Western blot analysis to determine the knockdown of DNMT3a at the protein level. However, available antibodies were not able to produce a specific band for DNMT3a in brain tissue, and we therefore rely on the above validation from the cellular knockdown. Mice were injected bilaterally into the MPFC with lentiviruses expressing shDnmt3a\#1. To verify our ability to deliver the lentiviruses precisely into the $\mathrm{mPFC}$, following a 2 -week recovery period, mice were anesthetized, perfused, and the perfused brains were sectioned and immunostained for GFP to confirm the exact infected sites (Fig. 2G-J).

\section{Knocking down Dnmt3a in the mPFC increases anxiety- like behavior}

After validation of the virus, adult mice were injected bilaterally with either shDnmt3a virus (KD group) or control viruses into the mPFC. To test the effects of Dnmt3a knockdown on anxiety-like behavior, we examined performance in the EPM. Mice that received injections with shRNA-Dnmt3a in the mPFC showed a significant reduction in the time spent in the open arms $\left(n=10\right.$ or $11, T_{(19)}=$ 2.524, $p=0.021$; Fig. $3 A)$ and in the total distance traveled in the open arms $(n=10$ or $11, U=18.00, p=0.009$, Mann-Whitney $U$ test; Fig. 3B). We also checked anxiety levels in another established anxiety test, the DLT test. In accordance with the EPM results, there was a significant reduction in the duration of time spent in the light $\left(n=20\right.$ or $21, T_{(39)}=2.201, p=0.034$; Fig. $\left.3 E\right)$, total distance traveled in the light $\left(n=20\right.$ or $21, T_{(39)}=2.631, p=0.012$; Fig. $\left.3 F\right)$, and in the number of visits to the light area $\left(n=20\right.$ or $21, T_{(39)}=$ $2.868, p=0.033$; Fig. $3 G$ ) relative to control virus-injected mice. To exclude behavioral changes associated with locomotor deficits, locomotor activity was evaluated across the circadian cycle. Comparing the Dnmt3a KD with the control group (using one-way ANOVA with repeated measures) revealed no significant difference between the groups (Fig. $3 \mathrm{H}, I$ ). The results of the behavioral tests showed that knocking down Dnmt3a in the mPFC is sufficient to mimic the increase in anxiety-like behavior following CSDS, which suggests that Dnmt3a in the mPFC plays a key role in mediating anxiety-like behavior.

\section{mPFC-Dnmt3a1 overexpression reduces baseline anxiety in adult mice}

As a complementary experiment, we used genetic tools to selectively overexpress Dnmt $3 \mathrm{a} 1$ in the $\mathrm{mPFC}$ and investigate its effect on baseline anxiety levels of adult mice.

To establish a Dnmt3a1 OE lentiviruses, the mouse Dnmt3a1 sequence was amplified and cloned into a GFP containing lentiviral vector, and lentiviruses were produced (Fig. 4A). To determine the efficiency of these viruses to overexpress Dnmt3a1, we compared the relative mRNA expression of Dnmt3a in the mPFC of mice injected with Dnmt3a OE lentivirus to mice injected with the control virus. Micro-punching of mPFC was performed 3 weeks after injection, and mRNA levels were determined using qRT-PCR. This revealed a significant increase in mPFC-Dnmt3a 

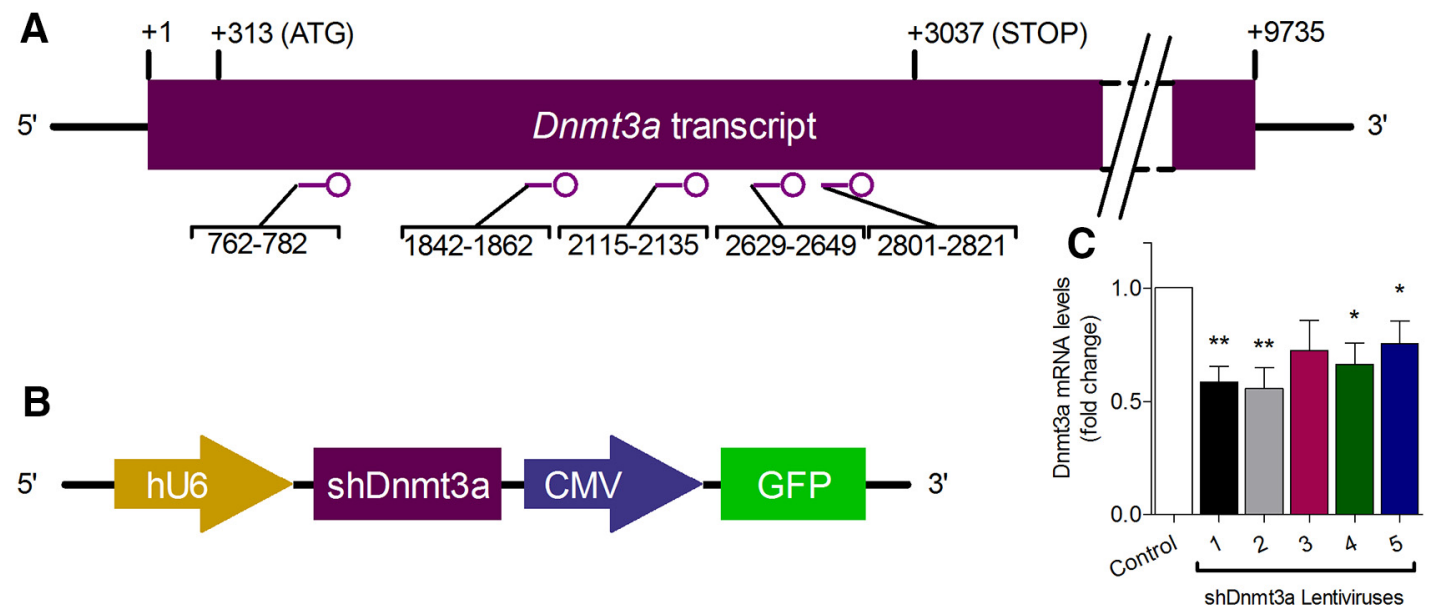

D

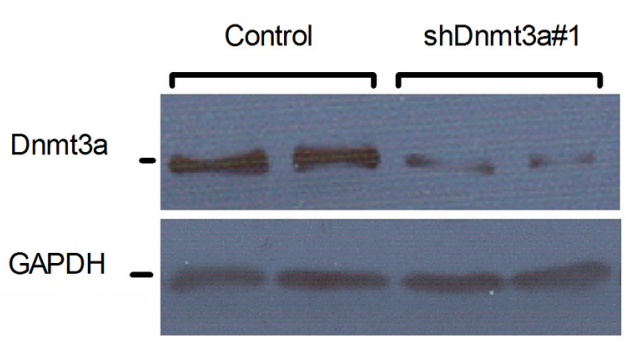

E
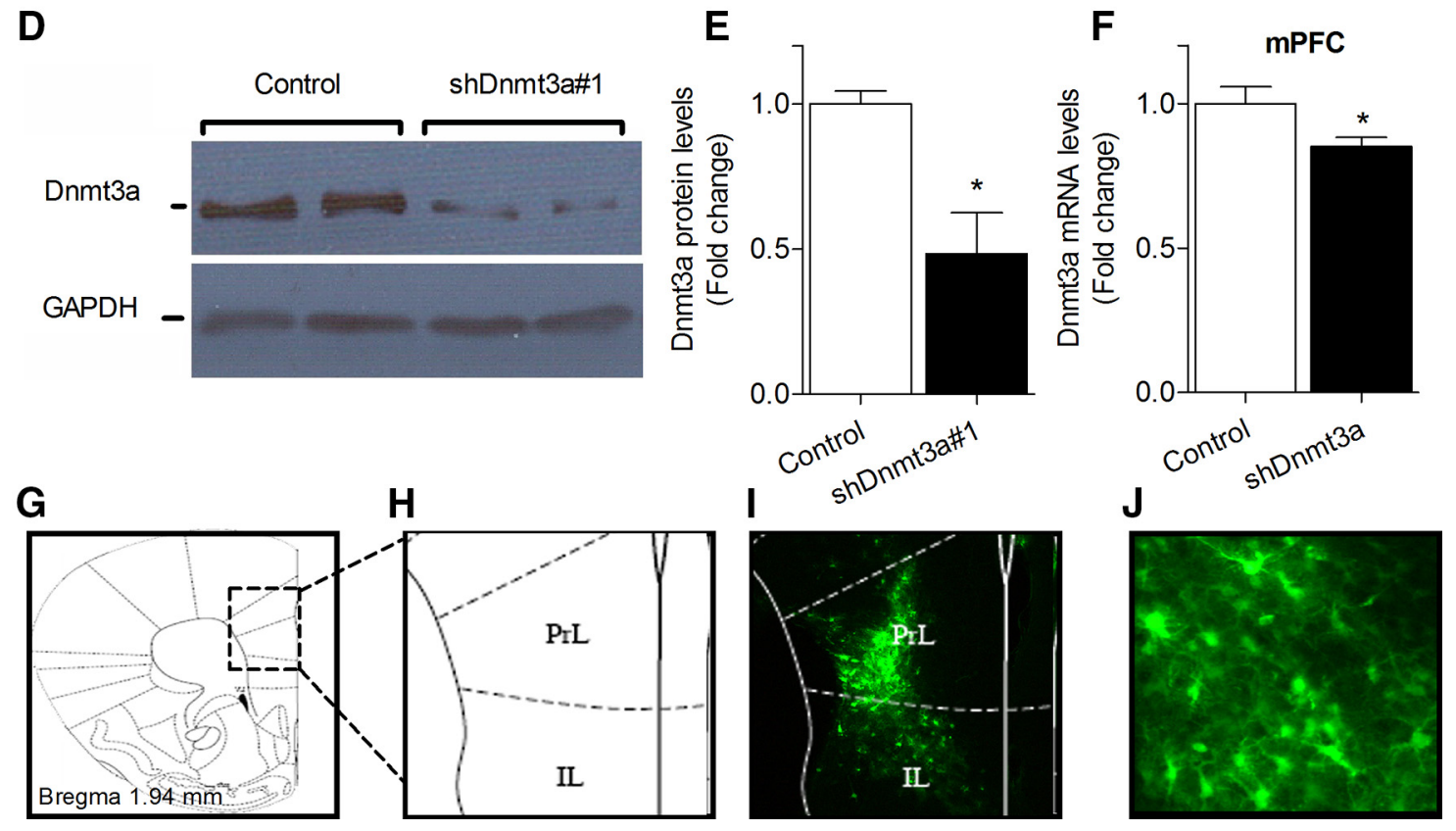

Figure 2. Lentiviral-based system used for the site-specific knockdown of Dnmt3a. $A$, Five different shRNA target sequences from the open reading frame of the mouse Dnmt3a gene were designed. $\boldsymbol{B}$, Schematic illustration of the shDnmt3a lentivirus constructs. $\mathbf{C}-\boldsymbol{E}$, In vitro validation of shDnmt3a lentiviral constructs. $\boldsymbol{C}$, Dnmt3a mRNA levels in N2a cells infected with the five different Dnmt3a-shRNA constructs determined using RT-PCR revealed that four constructs significantly reduced Dnmt3a mRNA levels, with Construct 1 and Construct 2 having the highest efficiency. $n=4$ (one-way ANOVA followed by Student's t test). $\boldsymbol{D}$, Western blot analysis followed by $(\boldsymbol{E})$ densitometry measurements show the ability of Virus 1 to reduce levels of Dnmt3a expression in N2a-infected cells. $n=4$ (Students' $t$ test). $\boldsymbol{F}$, In vivo validation of shDnmt3a viral construct. qRT-PCR determined a reduction in Dnmt3a mRNA levels in the brain tissue punches from the $\mathrm{mPFC}$ that were collected from shDnmt3a-injected mice compared with control injected mice. $n=8$ (Student's $t$ test). G-J, mPFC section of mice injected with shDnmt3a-GFP virus. G, Schematic representation of site of delivery adapted from Paxinos and Franklin digital mouse brain atlas. $\boldsymbol{H}$, Enlargement of the mPFC region corresponding to the injection site. $\boldsymbol{I}$, Representative microscope image of virally infected mPFC 2 weeks following lentiviral injection. J, Infected neurons at site of injection. PrL, Prelimbic cortex; IL, infralimbic cortex. ${ }^{*} p<0.05$, shDnmt 3 a versus controls. ${ }^{* *} p<0.01$, shDnmt 3 a versus controls. Data are mean \pm SEM.

mRNA expression in mice injected with Dnmt3a OE lentivirus $\left(n=4-8, T_{(10)}=-3.834, p=0.003\right.$; Fig. $\left.4 B\right)$. Lentiviruses expressing Dnmt3a or control viruses were bilaterally injected to the $\mathrm{mPFC}$ of adult C57BL/6 mice. Two weeks following the injections, mice were tested for anxiety-like behavior. In the EPM test, the mice injected with Dnmt3a OE showed a significant increase in the duration of time spent in the open arms $(n=$ $16-18, T_{(32)}=-2.828, p=0.008$; Fig. $\left.4 C\right)$, the total distance traveled in open arms $\left(n=16-18, T_{(32)}=-2.848, p=0.008\right.$; Fig. $4 D)$, and in the number of visits in the open arms $(n=$ $16-18, T_{(32)}=-2.389, p<0.023$; Fig. $\left.4 E\right)$. The DLT test revealed a significant increase in the total distance Dnmt3a-OE mice traveled in light compared with the control group $(n=16-18, U=$ 94, $p=0.05$; Fig. 4G). There were no differences in home cage locomotor activity between the groups (data not shown). These behavioral results, together with the results of Dnmt3a KD experiment, suggest that decreased Dnmt3a expression specifically in the $\mathrm{mPFC}$ increases anxiety-like behavior in adult mice, whereas increased Dnmt3a reduces anxiety levels.

\section{Restoring the levels of Dnmt3al in the mPFC reverses the increase in anxiety-like behavior in CSDS mice}

The potential of modulating Dnmts to "rescue" behavioral abnormalities has been previously proposed (LaPlant et al., 2010, Oliveira et al., 2012). We now report that there is a reduction in mPFC-Dnmt3a1 levels following CSDS. Additionally, we show that genetic manipulation of $\mathrm{mPFC}-\mathrm{Dnm} 3 \mathrm{3}$ levels has a robust effect on anxiety levels of adult mice. Considering these data, we 
A

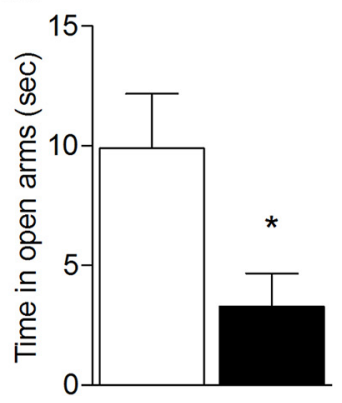

B

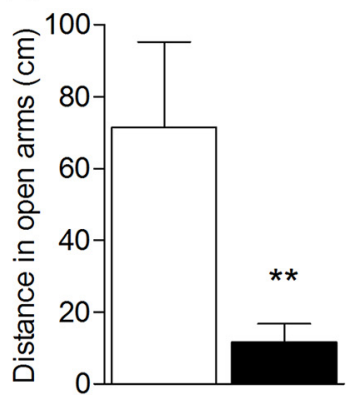

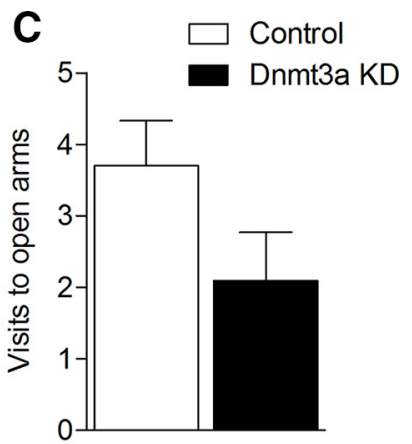
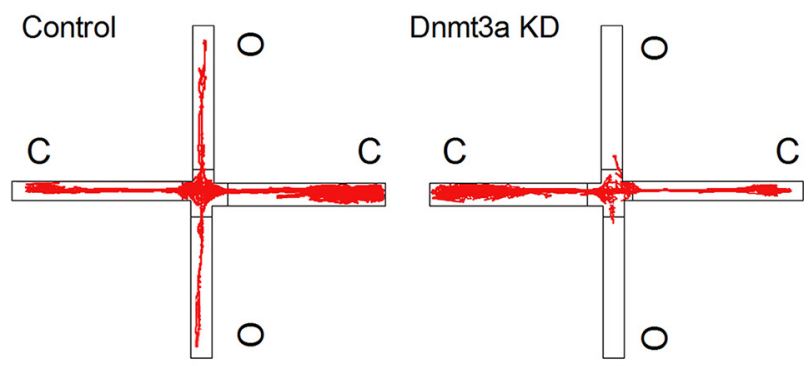

E

F
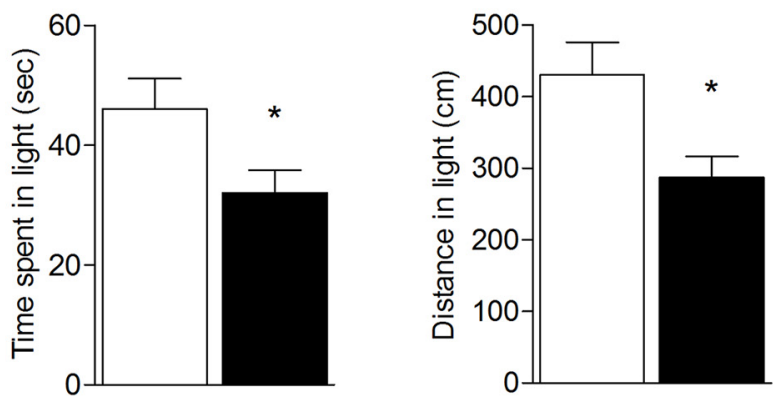

G

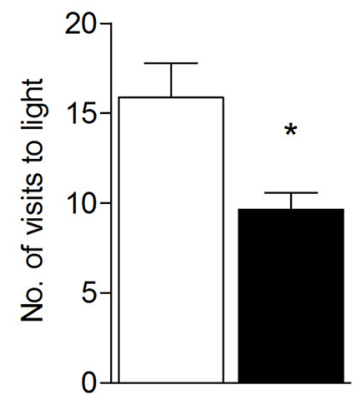

H

I

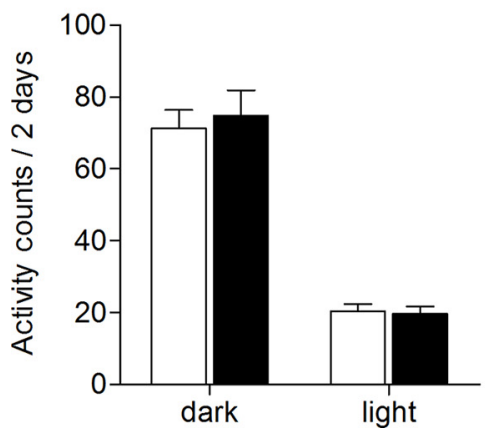

Figure 3. Increase in anxiety-like behavior in mice injected with shDnmt3a (Dnmt3a KD) construct in the mPFC. Dnmt3a KD mice showed significant reduction in the (A) total time spent in and $(\boldsymbol{B})$ total distance traveled in but $(\boldsymbol{C})$ made a similar number of entries into the open arms of the EPM compared with control mice. $\boldsymbol{D}$, Representative activity traces from control and Dnmt3a KD in the EPM. C, Closed arm; 0, open arm. $n=10$ or 11 (Mann-Whitney $U$ test). Dnmt3a KD mice showed a significant reduction in the $(\boldsymbol{E})$ time spent in and $(\boldsymbol{F})$ distance traveled in and $(\boldsymbol{G})$ made fewer entries to the light compartment in the DLT test. $n=20$ or 21 (Mann-Whitney $U$ test). $\boldsymbol{H}, \boldsymbol{I}$, Dnmt3a KD mice exhibit similar locomotor activity levels as control throughout the entire circadian cycle. $\boldsymbol{H}$, Activity pattern of Dnmt3a KD mice and control mice calculated in 30 min intervals during dark (gray background) and light cycles. $I$, Total activity during dark and light cycles. $n=9$ (one-way ANOVA with repeated measures). ${ }^{*} p<0.05$, Dnmt3a KD mice versus controls. ${ }^{* *} p<0.01$, Dnmt3a KD mice versus controls. Data are mean \pm SEM.

hypothesized that restoring the mPFC-Dnmt3a1 levels of CSDS mice may prevent the increase in their anxiety-like behavior. Therefore, we designed an experiment where mice were subjected to $10 \mathrm{~d}$ of CSDS and then were bilaterally injected with either Dnmt3a1 OE viruses or control viruses ( $n=12$ per group) specifically into the $\mathrm{mPFC}$. Following 2 weeks of recovery, the mice were tested for anxiety-like behavior (Fig. 5A). The results of the behavioral tests were quite conclusive, showing a clear reduction in the anxiety-like behavior of the CSDS mice that were injected with Dnmt3a1 OE virus. In the EPM test, the CSDS-Dnmt3a1 OE group showed reduced anxiety-like behavior exhibited by a significant increase in the time spent in the open arms $(n=11, U=$ 
A

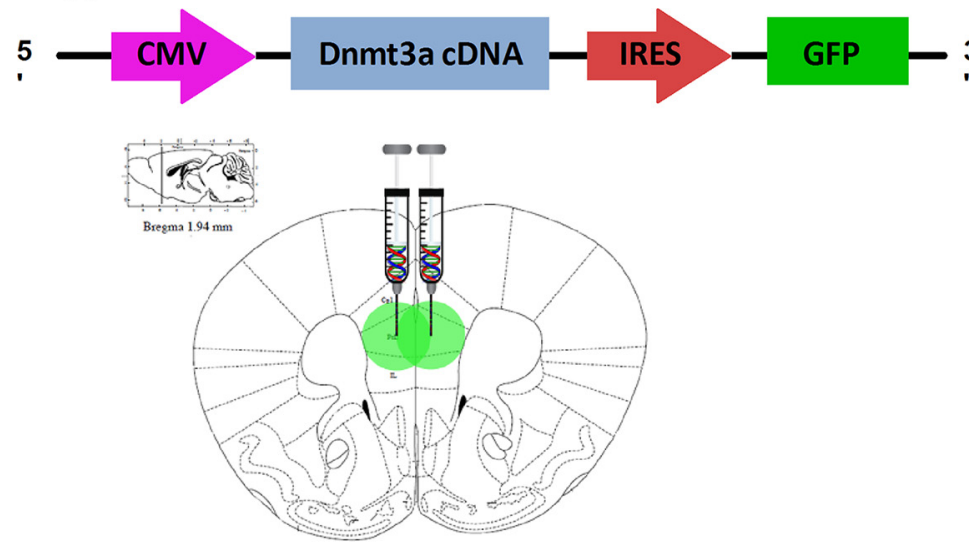

B

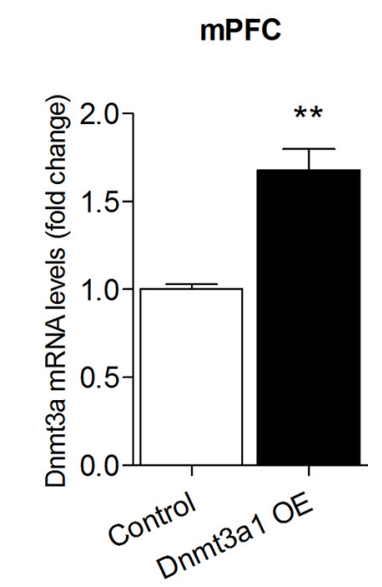

E

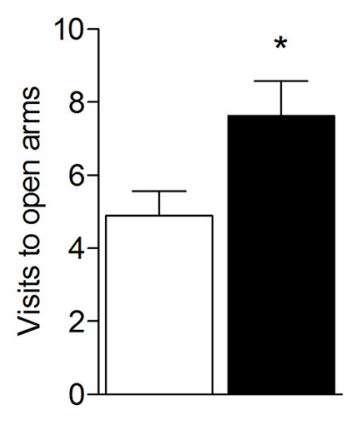

H

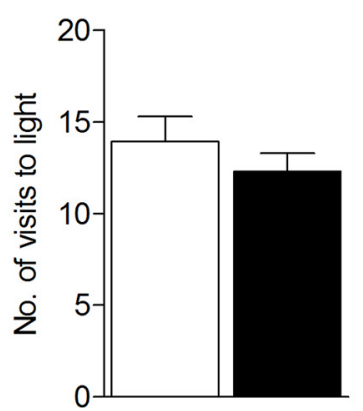

Figure 4. mPFC-Dnmt3a1 overexpression reduces baseline anxiety in adult mice. $A$, Schematic illustration of the Dnmt3a1 0 E lentivirus constructs and sites of injection (adapted from Paxinos and Franklin digital mouse brain atlas). $\boldsymbol{B}$, In vivo validation of Dnmt3a1 0 Eviral construct. $q$ RT -PCR determined an increase in Dnmt3a1 mRNA levels in the brain tissue punches from the $m$ PFC that were collected from Dnmt3a1 0E-injected mice compared with control injected mice. $n=4-8$ (Student's $t$ test). Dnmt3a1 0E mice showed significant elevation in the $(\boldsymbol{C})$ total time spent in, $(\boldsymbol{D})$ total distance traveled in, and $(\boldsymbol{E})$ number of entries into the open arms of the EPM compared with control mice. $n=16-18$ (Mann-Whitney $U$ test). G, Dnmt3a1 0E mice showed a significant elevation in distance traveled in the light compartment in the DLT test. No difference between the groups was found in the $(\boldsymbol{F})$ total time spend in or $(\boldsymbol{H})$ number of visits to the light chamber. $n=10-18$ (Mann-Whitney $U$ test). ${ }^{*} p<0.05$, Dnmt3a1 0 E mice versus controls. ${ }^{* *} p<0.01$, Dnmt3a1 0 E mice versus controls. Data are mean \pm SEM.

25.00, $p=0.035$; Fig. $5 B)$ and in the total distance traveled in the open arms $(n=11, U=24.50, p=0.032$, Mann-Whitney $U$ test; Fig. $5 C$ ). Similarly, the DLT test found significant differences between the CSDS-Dnmt3a1 OE and the CSDS-control group in the duration of time spent in the light $\left(n=11, T_{(20)}=-2.726\right.$, $p=0.013$; Fig. $5 E$ ) and in the total distance traveled in the light $\left(n=11, T_{(20)}=-2.708, p=0.014\right.$; Fig. $\left.5 F\right)$. No changes were observed in the motor activity of mice injected with Dnmt3a1 OE or control viruses (Fig. $5 H, I$ ). These behavioral results infer that restoring the levels of $\mathrm{mPFC}-\mathrm{Dnm} 3 \mathrm{a} 1$ in stressed mice has an anxiolytic effect.

\section{Discussion}

Our results suggest that Dnmt3a in the mPFC has a functional role in anxiety-like behavior and that the regulation of this gene may serve as a possible molecular link between chronic stress and the development of anxious behavior. In our initial experiments, we demonstrated that CSDS induced a persistent reduction in the expression of $\mathrm{mPFC}$-Dnmt3a1 that coincides with a reduction in the global methylation levels and with prolonged elevated anxious behavior. Considering the anatomical complexity of both the amygdala and PFC, it is highly possible that DNMTs are 


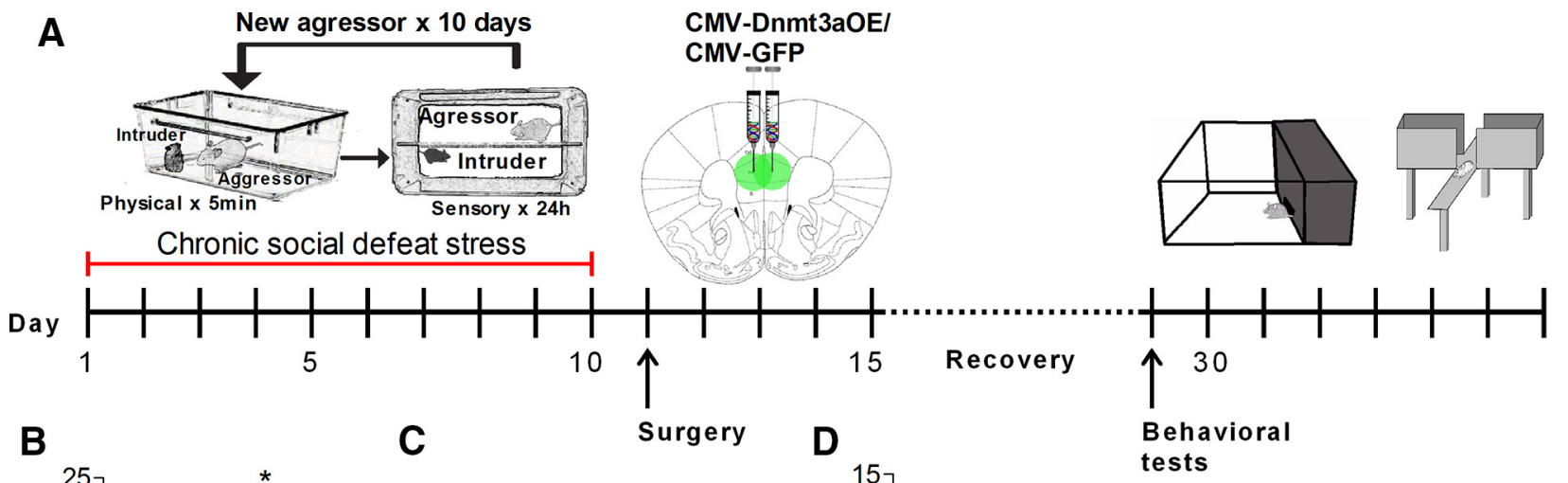

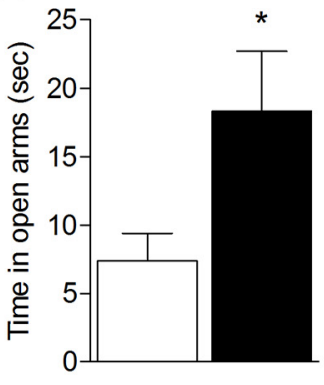

$\mathbf{E}$

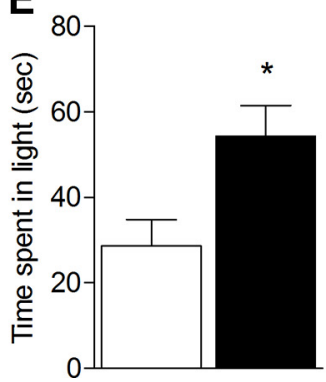

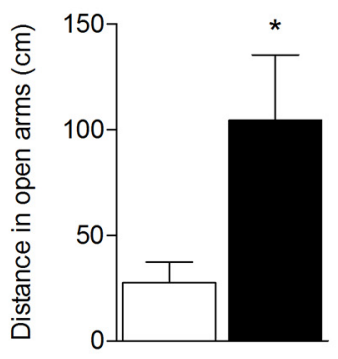

$\mathbf{F}$

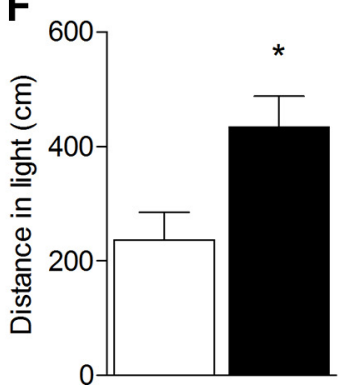

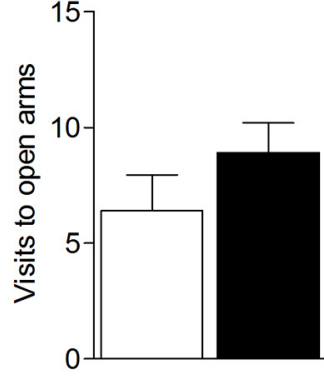

G

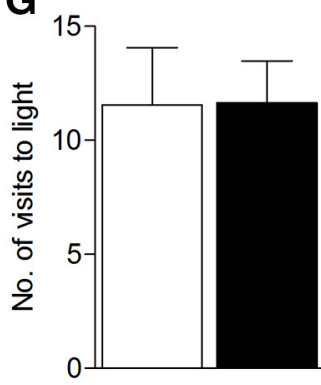

CSDS, CMV-GFP

CSDS, CMV-Dnmt3aOE

H

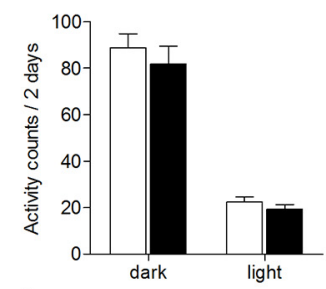

I

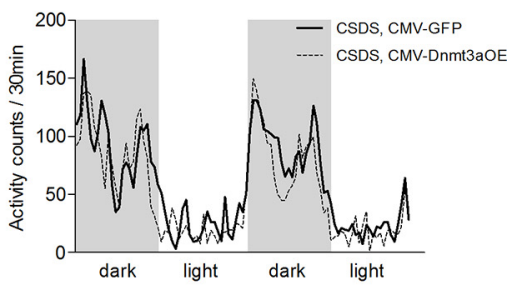

Figure 5. Restoring the levels of Dnmt3a in the mPFC reverses the increase in anxiety-like behavior in CSDS mice. A, Schematic illustration of the experiment's timeline. CSDS mice injected with mPFC-Dnmt3a OE showed a significant elevation in the $(\boldsymbol{B})$ total time spent in and $(\boldsymbol{C})$ total distance traveled in the open arms of the EPM but $(\boldsymbol{D})$ showed no significant difference in the number of visits to the open arms compared with CSDS mice that were injected with control virus. $n=11$ (Mann-Whitney $U$ test). The reduced anxiety levels of the CSDS-Dnmt3a 0E group were demonstrated also by a significant elevation in the $(\boldsymbol{E})$ time spent in and $(\boldsymbol{F})$ distance traveled in the light compartment in the DLT test. $\mathbf{G}$, A similar number of entries into the light compartment in the DLT test. $n=11$ (Students' $t$ test). $\boldsymbol{I}$, Activity pattern of CSDS-Dnmt3a 0E mice and control mice calculated in 30 min intervals during dark (gray background) and light cycles. $\boldsymbol{H}$, Total activity during dark and light cycles. $n=11$. (one-way ANOVA with repeated measures). ${ }^{*} p<0.05$, CSDS-Dnmt3a OE versus CSDS-control mice. Data are mean \pm SEM.

differentially regulated in subregions of these areas, therefore complicating our efforts to detect changes when sampling the whole region. Therefore, we specifically probed the CeA, which is a major output nucleus of the amygdala, and the mPFC, which has a high level of connectivity to the amygdala. Examining expression levels of different Dnmts across the limbic system showed that the effect of chronic stress on Dnmts' expression is brain region specific and variable between the different Dnmts. Glucocorticoid secretion is a prominent part of the stress response. One possible mechanism by which stress might regulate Dnmt3a expression may involve the modulation of the binding transcription factor, glucocorticoid receptor (NR3C1), to a negative glucocorticoid response element found $150 \mathrm{bp}$ upstream of the Dnmt3a transcription start site (Surjit et al., 2011). However, additional promoter analysis studies are needed to confirm the importance of this negative glucocorticoid response element for Dnmt3a expression levels.

In our functional experiments, we showed that knocking down mPFC-Dnmt3a in naive mice induced anxiety-like behavior, similarly to the effect of CSDS. Conversely, overexpressing this gene in the PFC had an anxiolytic effect. Our observations support an increasing line of evidence that dysregulation of Dn$\mathrm{mts}$ is causative of stress-induced behaviors and cognitive deficits. In a previous study, mice subjected to the CSDS procedure showed increased Dnmt3a expression levels in the NAc that was accompanied by increased depressive-like behavior (LaPlant et al., 2010). Additionally, impaired hippocampal-related memory tasks in aged mice were linked to reduced hippocampal Dnmt3a2 levels (Oliveira et al., 2012). Moreover, the importance of Dnmts was demonstrated in memory formation by using Dnmt1 and Dnmt3a double KO mice (Feng et al., 2010) and Dnmt inhibitors (Miller et al., 2010). Human studies have also suggested a role for Dnmts in psychopathologies. A postmortem study showed significant alterations in Dnmts levels in the frontopolar cortex of depressed suicide victims (Poulter et al., 2008). Expression of Dnmts was also found in the peripheral blood of patients suffering from major depressive disorder, which was not apparent when the same patients were in a remissive state (Higuchi et al., 2011).

Brain imaging and postmortem studies have reported lower PFC volumes in subjects with stress-related psychopathologies. Studies using animal models of chronic stress have shown a re- 
duction in the number of dendritic spines and function of neurons in the PFC (Radley et al., 2006; Liu and Aghajanian, 2008). Thus, chronic stress decreases neuronal activity in the PFC, weakening the structures that provide negative feedback in the stress response. In our results, stress induced a decrease in Dnmt3a levels in the $\mathrm{mPFC}$, whereas overexpression of Dnmt3al precipitated an increased ability to withstand stress-induced anxiety. Therefore, Dnmt3a appears to positively affect the ability of the mPFC to fulfill its role in the context of stress-induced behaviors. This finding is supported by previous reports of Dnmt3a expression appearing to positively correlate with increased activity in that brain region. For example, fear conditioning increases Dnmt3a expression in the hippocampus, and inhibition of Dn$\mathrm{mts}$ inhibits hippocampal-dependent fear learning in mice. In another notable study, an increase of Dnmt3a expression in the NAc was observed following chronic social stress (LaPlant et al., 2010). The same research group previously showed that the NAc is overactivated following CSDS (Berton et al., 2006). At the cellular level, Dnmt3a overexpression increased spinal density in the NAc, and inhibition of Dnmts in cell cultures inhibited long-term potentiation. Contrary to the PFC, the amygdala increases in volume under chronic stress and studies in rodents have shown that prolonged stress causes dendritic hypertrophy in the amygdala (Vyas et al., 2002), which leads to hyperactivity in this brain region. In support of our hypothesis, we observed increased expression of Dnmt3a in the CeA following CSDS.

While previous evidence indicates that Dnmt3a regulates spinal density, long-term potentiation, and trauma-induced behaviors, we still do not appreciate how Dnmt3a performs these functions at the level of regulation of gene transcription. Several lines of evidence have suggested a possible link between modification in DNA methylation patterns of particular genes to neuropsychiatric disorders in humans and in animal models for depression and anxiety disorders (Weaver et al., 2004; Oberlander and Weinberg, 2008; McGowan et al., 2009; Murgatroyd et al., 2009; Elliott et al., 2010; Keller et al., 2010; Uchida et al., 2011). However, most of these studies have concentrated on DNA methylation of genes that are known to be central to stressrelated behaviors, and not particularly involved in synaptic or electrophysiological properties. Therefore, it is not clear how Dnmt3a may help to promote the function of specific brain regions or increase synaptic function. Dnmt3a regulation of gene expression is rather complex; and although binding to the promoter region can lead to gene silencing, Dnmt3a binding to nonpromoter regions of a gene promotes gene expression (Wu et al., 2010). We speculate that the effect of prolonged stress on synaptic plasticity, as demonstrated by hypotrophy in the MPFC (Radley et al., 2004) and hypertrophy in the NAc (LaPlant et al., 2010), is partly mediated through Dnmt3a modification on the expression of a subset of synaptic genes. Therefore, it is possible that the Dnmt3a-induced resiliency to stress-induced anxiety is mediated through the increased expression of synaptic genes in the PFC; however, this hypothesis needs experimental investigation in future studies.

Our study suggests that the effects of stress-induced anxiety can be mediated through the modulation of Dnmt3a expression. Because Dnmt3a overexpression in the mPFC was able to attenuate stress-induced anxiety, we propose that Dnmt3a is a primary enzyme involved in the stress response, and continued experimentation into Dnmt inhibition and overexpression in various brain regions is highly warranted.

\section{References}

Arnsten AF (2009) Stress signalling pathways that impair prefrontal cortex structure and function. Nat Rev Neurosci 10:410-422. CrossRef Medline

Berton O, McClung CA, Dileone RJ, Krishnan V, Renthal W, Russo SJ, Graham D, Tsankova NM, Bolanos CA, Rios M, Monteggia LM, Self DW, Nestler EJ (2006) Essential role of BDNF in the mesolimbic dopamine pathway in social defeat stress. Science 311:864-868. CrossRef Medline

Elliott E, Ezra-Nevo G, Regev L, Neufeld-Cohen A, Chen A (2010) Resilience to social stress coincides with functional DNA methylation of the Crf gene in adult mice. Nat Neurosci 13:1351-1353. CrossRef Medline

Feng J, Zhou Y, Campbell SL, Le T, Li E, Sweatt JD, Silva AJ, Fan G (2010) Dnmt1 and Dnmt3a maintain DNA methylation and regulate synaptic function in adult forebrain neurons. Nat Neurosci 13:423-430. CrossRef Medline

Herman JP, Ostrander MM, Mueller NK, Figueiredo H (2005) Limbic system mechanisms of stress regulation: hypothalamo-pituitaryadrenocortical axis. Prog Neuropsychopharmacol Biol Psychiatry 29: 1201-1213. CrossRef Medline

Higuchi F, Uchida S, Yamagata H, Otsuki K, Hobara T, Abe N, Shibata T, Watanabe Y (2011) State-dependent changes in the expression of DNA methyltransferases in mood disorder patients. J Psychiatr Res 45:12951300. CrossRef Medline

Keller S, Sarchiapone M, Zarrilli F, Videtic A, Ferraro A, Carli V, Sacchetti S, Lembo F, Angiolillo A, Jovanovic N, Pisanti F, Tomaiuolo R, Monticelli A, Balazic J, Roy A, Marusic A, Cocozza S, Fusco A, Bruni CB, Castaldo G, et al. (2010) Increased BDNF promoter methylation in the Wernicke area of suicide subjects. Arch Gen Psychiatry 67:258267. CrossRef Medline

Krishnan V, Han MH, Graham DL, Berton O, Renthal W, Russo SJ, Laplant Q, Graham A, Lutter M, Lagace DC, Ghose S, Reister R, Tannous P, Green TA, Neve RL, Chakravarty S, Kumar A, Eisch AJ, Self DW, Lee FS, et al. (2007) Molecular adaptations underlying susceptibility and resistance to social defeat in brain reward regions. Cell 131:391-404. CrossRef Medline

LaPlant Q, Vialou V, Covington HE 3rd, Dumitriu D, Feng J, Warren BL, Maze I, Dietz DM, Watts EL, Iñiguez SD, Koo JW, Mouzon E, Renthal W, Hollis F, Wang H, Noonan MA, Ren Y, Eisch AJ, Bolaños CA, Kabbaj M, et al. (2010) Dnmt3a regulates emotional behavior and spine plasticity in the nucleus accumbens. Nat Neurosci 13:11371143. CrossRef Medline

Liu RJ, Aghajanian GK (2008) Stress blunts serotonin- and hypocretinevoked EPSCs in prefrontal cortex: role of corticosterone-mediated apical dendritic atrophy. Proc Natl Acad Sci U S A 105:359-364. CrossRef Medline

McGowan PO, Sasaki A, D’Alessio AC, Dymov S, Labonté B, Szyf M, Turecki G, Meaney MJ (2009) Epigenetic regulation of the glucocorticoid receptor in human brain associates with childhood abuse. Nat Neurosci 12: 342-348. CrossRef Medline

Miller CA, Sweatt JD (2007) Covalent modification of DNA regulates memory formation. Neuron 53:857-869. CrossRef Medline

Miller CA, Gavin CF, White JA, Parrish RR, Honasoge A, Yancey CR, Rivera IM, Rubio MD, Rumbaugh G, Sweatt JD (2010) Cortical DNA methylation maintains remote memory. Nat Neurosci 13:664-666. CrossRef Medline

Murgatroyd C, Patchev AV, Wu Y, Micale V, Bockmühl Y, Fischer D, Holsboer F, Wotjak CT, Almeida OF, Spengler D (2009) Dynamic DNA methylation programs persistent adverse effects of early-life stress. Nat Neurosci 12:1559-1566. CrossRef Medline

Oberlander TF, Weinberg J, Papsdorf M, Grunau R, Misri S, Devlin AM (2008) Prenatal exposure to maternal depression, neonatal methylation of human glucocorticoid receptor gene (NR3C1) and infant cortisol stress responses. Epigenetics 3:97-106. CrossRef Medline

Oliveira AM, Hemstedt TJ, Bading H (2012) Rescue of aging-associated decline in Dnmt3a2 expression restores cognitive abilities. Nat Neurosci 15:1111-1113. CrossRef Medline

Poulter MO, Du L, Weaver IC, Palkovits M, Faludi G, Merali Z, Szyf M, Anisman H (2008) GABAA receptor promoter hypermethylation in suicide brain: implications for the involvement of epigenetic processes. Biol Psychiatry 64:645-652. CrossRef Medline

Radley JJ, Sisti HM, Hao J, Rocher AB, McCall T, Hof PR, McEwen BS, 
Morrison JH (2004) Chronic behavioral stress induces apical dendritic reorganization in pyramidal neurons of the medial prefrontal cortex. Neuroscience 125:1-6. CrossRef Medline

Radley JJ, Rocher AB, Miller M, Janssen WG, Liston C, Hof PR, McEwen BS, Morrison JH (2006) Repeated stress induces dendritic spine loss in the rat medial prefrontal cortex. Cereb Cortex 16:313-320. CrossRef Medline

Roth TL (2013) Epigenetic mechanisms in the development of behavior: advances, challenges, and future promises of a new field. Dev Psychopathol 25:1279-1291. CrossRef Medline

Roth TL, Lubin FD, Funk AJ, Sweatt JD (2009) Lasting epigenetic influence of early-life adversity on the BDNF gene. Biol Psychiatry 65:760-769. CrossRef Medline

Surjit M, Ganti KP, Mukherji A, Ye T, Hua G, Metzger D, Li M, Chambon P (2011) Widespread negative response elements mediate direct repression by agonist-liganded glucocorticoid receptor. Cell 145:224-241. CrossRef Medline

Sztainberg Y, Kuperman Y, Tsoory M, Lebow M, Chen A (2010) The anxiolytic effect of environmental enrichment is mediated via amygdalar CRF receptor type 1. Mol Psychiatry 15:905-917. CrossRef Medline
Tiscornia G, Singer O, Verma IM (2006) Production and purification of lentiviral vectors. Nat Protoc 1:241-245. CrossRef Medline

Uchida S, Hara K, Kobayashi A, Otsuki K, Yamagata H, Hobara T, Suzuki T, Miyata N, Watanabe Y (2011) Epigenetic status of Gdnf in the ventral striatum determines susceptibility and adaptation to daily stressful events. Neuron 69:359-372. CrossRef Medline

Vyas A, Mitra R, Shankaranarayana Rao BS, Chattarji S (2002) Chronic stress induces contrasting patterns of dendritic remodeling in hippocampal and amygdaloid neurons. J Neurosci 22:6810-6818. Medline

Weaver IC, Cervoni N, Champagne FA, D’Alessio AC, Sharma S, Seckl JR, Dymov S, Szyf M, Meaney MJ (2004) Epigenetic programming by maternal behavior. Nat Neurosci 7:847-854. CrossRef Medline

Wu H, Coskun V, Tao J, Xie W, Ge W, Yoshikawa K, Li E, Zhang Y, Sun YE (2010) Dnmt3a-dependent nonpromoter DNA methylation facilitates transcription of neurogenic genes. Science 329:444-448. CrossRef Medline

Yehuda R, LeDoux J (2007) Response variation following trauma: a translational neuroscience approach to understanding PTSD. Neuron 56: 19-32. CrossRef Medline 